Revista de Derecho

de la Pontificia Universidad Católica de Valparaíso XXXIII (Valparaíso, Chile, $2^{\text {do }}$ Semestre de 2009)

[pp. 621-638]

\title{
MÁS ALLÁ DE LA CARIDAD. DE LOS DERECHOS NEGATIVOS A LOS DEBERES POSITIVOS GENERALES*
}

["Beyond Charity. From Negative Rights to General Positive Duties"]

\author{
AlejandRa ZúNiga Fajuri** \\ Universidad de Valparaíso, Chile
}

\begin{abstract}
RESUMEN
En este artículo se analizan los argumentos que, de manera más concluyente, permiten la fundamentación moral y defensa de los derechos económicos, sociales y culturales, así como de aquellos razonamientos que revelan la arbitrariedad y añeja distinción que se ha querido mantener entre ellos y los derechos civiles y políticos. Junto con la revisión de la polémica en torno a los llamados "Deberes Positivos Generales", se concluye que la satisfacción de las necesidades básicas de los individuos, por medio del reconocimiento de la exigibilidad de los derechos económicos, sociales y culturales y de la extensión de la obligación de su satisfacción a todas las personas,
\end{abstract}

\begin{abstract}
This essays review some conclusive argument to defend social, economic and cultural rights, as well of those reasoning that analyzed and reveal the abuse and ages distinction that have been wanted to maintain that difference. Along with the revision of the controversy around "General Positive Duties", conclude that the satisfaction of basic needs, by means of the recognition of the demandability of the economic, social and cultural rights and the extension of the obligation of its satisfaction to all the people, is fundamental for the construction of democratic societies formed by capable individuals with dignity and moral autonomy.
\end{abstract}

* Este artículo forma parte del proyecto de investigación № 11080005 financiado por el Fondo Nacional de Desarrollo Científico y Tecnológico (FONDECYT), titulado "Teorías de la justicia y Reforma Sanitaria AUGE".

** Doctora en Derecho por la Universidad Autónoma de Madrid. Docente e investigadora de la Escuela de Derecho de la Universidad de Valparaíso. Dirección: Errázuriz 2120. Valparaíso. Chile. Correo electrónico: alejandra.zuniga@uv.cl. 
es fundamental para la construcción de sociedades democráticas formadas por individuos capaces de dignidad y autonomía moral.

Palabras Clave: Derechos civiles y políticos - Derechos sociales - Deberes positivos generales - Autonomía - Libertad.
KeYwORDs: Civil and political rights - Social rights - General positive duties - Autonomy - Freedom.

\section{INTRODUCCIÓN}

El pensamiento jurídico contemporáneo ha desarrollado con lujo de detalles un concepto de "derecho subjetivo" que, si bien resulta apto para fundamentar la técnica jurídica del liberalismo económico y ciertos derechos humanos, parece inadecuado para cimentar filosóficamente otros derechos humanos ${ }^{1}$. Esa dificultad, con todo, no es insalvable pues los intentos que se han realizados para justificar la existencia y dar contenido a los llamados "derechos sociales" -como el derecho a la protección de la salud, a la vivienda, a la educación, a la previsión, etc.- hoy han alcanzado una solidez teórica que, en mi opinión, permite su defensa exitosa.

En este artículo se analizan los argumentos que, de manera más concluyente, permiten la fundamentación moral y defensa de los derechos económicos, sociales y culturales, así como de aquellos razonamientos que revelan la arbitrariedad y añeja distinción que se ha querido mantener entre ellos y los derechos civiles y políticos. Junto con la revisión de la polémica en torno a los llamados "Deberes Positivos Generales", se concluye que la satisfacción de las necesidades básicas de los individuos, por medio del reconocimiento de la exigibilidad de los derechos económicos, sociales y culturales y de la extensión de la obligación de su satisfacción a todas las personas, es fundamental para la construcción de sociedades verdaderamente democráticas formadas por individuos capaces de dignidad y autonomía moral.

\section{DERECHOS POSITIVOS Y DERECHOS NEGATIVOS ¿UNA DISTINCIÓN AÑEJA?}

Según la clásica tipología de W. H. Hohfeld todos los derechos son "ventajas legales" en el sentido de que sirven de distinta forma para proteger los intereses de sus titulares. A su vez, los "derechos subjetivos" son

${ }^{1}$ Hierro, Liborio, ¿Derechos humanos o necesidades humanas? Problemas de un concepto, sistema (Madrid, 1982), p. 46. 
posiciones normativas por las cuales un determinado sujeto tiene una libertad resguardada para actuar, una pretensión para beneficiarse de una conducta ajena, una potestad para ordenar la conducta de otro sujeto y una inmunidad frente a la potestad de otros. Dentro de su clasificación se distingue entre "derechos-demanda" y "derechos-libertades" o, lo que es lo mismo, los clásicos "derechos positivos" y "derechos negativos". Para dicha clasificación los derechos negativos -como el derecho a la libre expresión o el derecho de propiedad- involucran deberes de no interferencia en el ejercicio libre del derecho, mientras que los derechos positivos implican deberes de ayudar al titular del derecho a obtener el objeto de ese derecho, como por ejemplo, el derecho a la educación o el derecho al cuidado sanitario ${ }^{2}$.

Las objeciones más importantes en contra de los derechos fundamentales sociales pueden ser agrupadas, según Alexy, en dos argumentos complejos, uno formal y otro material. El argumento formal aduce un dilema: si los derechos fundamentales sociales son vinculantes, conducen a un desplazamiento de la política social desde la competencia del parlamento a la del Tribunal Constitucional. Debido a los efectos financieros de los derechos fundamentales sociales, y a causa de los considerables costos vinculados a su cumplimiento, la existencia de derechos fundamentales sociales amplios judicialmente imponibles conduciría a que la política presupuestaria estaría determinada, en parte esencial, por el derecho constitucional. El argumento material, por su parte, arguye que estos derechos son irreconciliables con normas constitucionales materiales $\mathrm{o}$, al menos, entran en colisión con ellas pues ¿cómo va el Estado a financiar su cumplimiento? Como todos los derechos fundamentales sociales son muy costosos, para su observancia el Estado sólo podrá distribuir aquello que, bajo la forma de tasas e impuestos, obtiene de otros sin lesionar sus derechos fundamentales ${ }^{3}$. Por ello, en la medida en que las normas constitucionales materiales confieren derechos de libertad, este sería un argumento de libertad en contra de los derechos fundamentales sociales.

Se puede objetar lo anterior sobre la base de la idea de que la determinación de cuáles son los derechos fundamentales sociales que el individuo posee definitivamente es un asunto de ponderación entre principios. Para Alexy, las prestaciones jurídicas serían "iusfundamentalmente" debidas si: i) la exige muy urgentemente el principio de la libertad fáctica; y ii) el

${ }^{2}$ Para Hohfeld los "deberes" son situaciones negativas pues implican limitar la capacidad de acción de los sujetos: HoHFEld, Wesley Newcomb, Some Fundamental Legal Conceptions as Applied to Judicial Reasoning, en Yale Law Journal 23 (1913).

${ }^{3}$ AleXY, Robert, Teoría de los derechos fundamentales (Centro de Estudios Políticos y Constitucionales. Madrid, 2002), pp. 490-493. 
principio de la división de poderes y el de la democracia (que incluye la competencia presupuestaria del Parlamento) al igual que: c) los principios materiales opuestos (especialmente aquellos que apuntan a la libertad jurídica de otros) son afectados en una medida relativamente reducida. "Estas condiciones están satisfechas en el caso de los derechos fundamentales sociales mínimos, es decir, por ejemplo, a un mínimo vital, a una vivienda simple, a la educación escolar, a la formación profesional y a un nivel mínimo de asistencia médica" ${ }^{4}$. En conclusión, de la ponderación de principios se deduce que el individuo tiene un derecho definitivo a la prestación cuando el principio de la libertad fáctica tiene un peso mayor que los principios formales y materiales opuestos tomados en su conjunto. Éste es el caso de los derechos mínimos5.

Holmes y Sunstein consideran que todos los derechos legalmente obligatorios son necesariamente derechos positivos. La palabra "positivo" puede utilizarse como opuesto a derecho moral y, también, como derechos que tienen una protección legal y que, por ello, suponen un interés calificable como derecho y un sistema legal efectivo que lo defienda con el uso de recursos colectivos ${ }^{6}$. De este modo, los autores quieren recalcar que, cuando nos centramos en el costo de los derechos, no queda más remedio que sostener que todos los derechos son positivos. En efecto, no es correcto argüir que los derechos sociales no son derechos humanos por estar limitados por falta de recursos económicos haciendo más probable su incumplimiento ¿y el incumplimiento masivo de ciertos derechos civiles y políticos como, por ejemplo, del derecho a la vida por razones económicas? Para Alfonso Ruiz Miguel no se puede identificar un derecho humano atendiendo sólo al coste del mismo pues ningún derecho es gratuito y, aunque el "precio" de los derechos sociales de prestación pueda ser comparativamente alto -en particular por la expansividad de su demanda- "el argumento del límite de los recursos no siempre apela a una imposibilidad fáctica sino que a veces presupone un criterio ideológico sobre cuánto y en qué es apropiado invertir o gastar" los derechos de libertad pues, por ejemplo, el derecho de huelga y el de sindicalización -dos derechos sociales- no parecen implicar grandes costes para el Estado, en cambio el derecho de libertad asociado a las elecciones

${ }^{4}$ Ibíd., pp. 494-495.

${ }^{5}$ Ibíd., pp. 495-499.

${ }^{6}$ Holmes, S. - Sunstein, C. R., The Cost of Rights: Why Liberty Depends on Taxes (Nueva York, W.W. Norton \& CO., 1999), pp. 17-43.

${ }^{7}$ Ruiz Miguel, Alfonso, Derechos liberales y derechos sociales, en Doxa 15-16 (1994), pp. 659-660. 
políticas o el derecho a la asistencia letrada para detenidos sin abogado sí son derechos de alto costo ${ }^{8}$.

Con todo, es necesario reconocer con Gewirth que centrarse sólo en el "valor" de los derechos para su clasificación confunde el costo de un derecho con su "contenido" pues, aunque es cierto que todos los derechos, para ser efectivamente gozados, deben ser implementados y protegidos por el gobierno a un cierto costo, eso no significa que su contenido, su objeto -a lo que se tiene derecho- deba ser también proporcionados por el gobierno'. En la misma línea Prieto Sanchís estima que, si la protección de todos los derechos supone una mínima estructura estatal, la de los derechos sociales resulta mucho más compleja, dado que ha de contar con una organización de servicios y prestaciones públicas sólo conocida por el Estado contemporáneo. Luego ¿es el carácter prestacional de los derechos sociales lo que los distingue de los derechos civiles y políticos? Si fuera así, todos los derechos fundamentales merecerían llamarse prestacionales dado que todos ellos exigen en mayor o menor medida una organización estatal que permita su ejercicio o que los defienda frente a intromisiones ilegítimas, o también el diseño de formas de participación; desde la tutela efectiva al derecho a voto, todos requieren de esas prestaciones en sentido amplio $^{10}$. Como observa Pérez Luño, ni en el plano de la fundamentación, ni en el de la formulación jurídica ni, en fin, en el de titularidad procede trazar una separación estricta entre derechos civiles y sociales ${ }^{11}$.

Luego, como todos los derechos básicos son, de alguna manera, "prestacionales", para distinguir entre el valor y el contenido de un derecho podemos seguir a Alexy que reconoce tres tipos de derechos a prestación: el derecho a protección, el derecho a organización y procedimiento y el derecho a prestación en sentido estricto ${ }^{12}$. Los derechos a prestaciones en sentido estricto son derechos del individuo frente al Estados a algo que -si el individuo poseyera medios financieros suficientes y si encontrase en el mercado una oferta suficiente- podría obtener también de particulares. Cuando se habla de derechos sociales fundamentales, por ejemplo, dere-

${ }^{8}$ Ibíd., p. 660.

${ }^{9}$ Gewirth, Alan, ¿Are All Rights Positive? en Philosophy \& Public Affairs 30 (2002) 3, p. 330 .

${ }^{10}$ Prieto SAnChís, Luis, Los derechos sociales y el principio de igualdad sustancial. Derechos sociales y derechos de las minorías, en Carbonell, M. - Cruz Parcero. J. A. VÁzQuez, R. (compiladores) (México, Universidad Nacional Autónoma de México, 2000), pp. 20-21.

${ }^{11}$ Pérez Luño, Antonio, Derechos humanos, Estado de derechos y Constitución (Madrid, Tecnos, 2004), p. 90.

${ }^{12}$ Alexy, R., cit. (n. 3), pp. 430 ss. 
cho a la protección de la salud, a la previsión, al trabajo, a la vivienda y la educación, se hace primariamente referencia a derechos a prestaciones en sentido estricto ${ }^{13}$, recalcando el contenido del derecho, más que el costo o valor del mismo.

Carlos Nino defiende que una concepción liberal de los derechos sociales no debe entenderlos en oposición a los derechos individuales pues, en tanto extensión natural, no serían diferentes del derecho a la vida, a la integridad personal y a los demás que se refieren a bienes necesarios para la autonomía personal, a condiciones para el goce de esos derechos ${ }^{14}$. Con estas ideas el filósofo respondía a la tesis de libertaristas que, como Hayek, argumentan que la justicia se materializa esencialmente en reglas negativas que prohíben la interferencia en el orden espontáneo del mercado - "cosmos"-y que sólo requieren acciones positivas en circunstancias muy especiales en las que existe algún tipo de compromiso voluntario y para quienes el concepto de justicia social es absolutamente vacío. Carecería de sentido, para estos libertaristas, hablar de "derechos sociales" pues no podría haber derechos sin la correspondiente obligación "y en este caso no existiría tal obligación correlativa, fundamentalmente por la razón de que es imposible identificar quién sería su sujeto obligado"15.

Varias son, con todo, las confusiones de una tesis como esta. La principal de ellas, sugiere Nino, es suponer que el orden del mercado es un orden espontáneo. Nada estaría más alejado de la verdad pues, en primer lugar, el orden del mercado está basado en la estructura de la propiedad que, como es obvio, es establecida por leyes estatales promulgadas y aplicadas deliberadamente, las cuales convalidan ciertos actos de posesión y de transferencia de bienes que podrían no ser reconocidos; les atribuyen ciertos derechos y obligaciones -que pueden tener distintos alcances- y establecen sanciones penales contra quienes interfieren en esos derechos. En segundo lugar, esas leyes son aplicadas por tribunales y cuerpos policíacos que son sostenidos a través de ingresos derivados de las obligaciones positivas de pagar contribuciones. En tercer lugar, el mercado opera a través de contratos que, para poder hacerse valer, también requieren de leyes, tribunales, cuerpos policíacos y contribuciones ${ }^{16}$. En el mismo sentido argumentan Abramovich y Courtis al estimar que "quienes rechazamos esta distinción -entre derechos positivos y negativos- lo hacemos sobre la

\footnotetext{
${ }^{13}$ Ibíd., p. 482.

${ }^{14}$ Nino, Carlos Santiago, Sobre los derechos sociales. Derechos sociales y derechos de las minorias, en Carbonell, M. - Cruz Parcero, J. A. - Vázquez, R. (compiladores), cit. (n. 12), p. 137.

${ }^{15}$ Ibíd., pp. 137-138.

${ }^{16}$ Ibíd., p. 138.
} 
base de que ella olvida que, incluso los pensadores más caracterizados con la economía política clásica, como A. Smith o D. Ricardo, consideraban obvia la interrelación entre las obligaciones positivas y negativas del Estado, en especial en materia de garantías de la libertad de comercio y de una larga serie de obligaciones positivas vinculadas con el mantenimiento de las instituciones políticas, judiciales, de seguridad y de defensa necesarias para el ejercicio de la libertad individual" ${ }^{17}$.

Todos los derechos, insiste por su parte Henry Shue, imponen deberes positivos y negativos. Tómese por ejemplo el derecho a la seguridad física: será respetado siempre que las personas se abstengan de atacar a otras y siempre y cuando el Estado tome las medidas necesarias para proteger a sus ciudadanos. En otras palabras, se trata de un derecho que impone tanto un deber de tipo negativo como otro positivo que incluye el de proveer de policías, tribunales penales, penitenciarías, escuelas de entrenamiento policiaco, abogados, guardias etc., todo lo cual, por cierto, debe ser financiado con impuestos capaces de costear el enorme sistema que se requiere para prevenir, detener y castigar las violaciones a la seguridad personal ${ }^{18}$. En fin, la distinción clásica entre deberes positivos y negativos (y derechos positivos y negativos) puede aparecer como artificial cuando se la quiere fundamentar sólo en base a los "montos" asociados a la satisfacción de cada derecho ${ }^{19}$. Y es que, además, si nos concentramos en los fundamentos morales que estarían detrás de los reclamos de satisfacción de los derechos sociales, podremos constatar que los manidos argumentos que insisten en jerarquizar derechos se diluyen aún más pues las razones para exigir su cumplimiento son, básicamente, las mismas. Para Jacobs, lo central es la idea de ciudadanía, es decir, que algunas personas deben ayudar a otras a ejercer su ciudadanía simplemente en virtud de esa "ciudadanía compartida". En este sentido, los derechos sociales serían necesarios para asegurar los derechos de libertad de sus titulares ya que si realmente se valora la libertad individual, entonces debiéramos preocuparnos de que todas las personas posean los medios necesarios para ejercer esa libertad ${ }^{20}$.

${ }^{17}$ Abramovich, Víctor - Courtis, Christian, Los derechos sociales como derechos exigibles (Madrid, Trotta, 2002), pp. 19-36.

${ }^{18}$ Shue, Henry, Basic Rights (2a edición, Princeton University Press, 1996), pp. 37-38. No todos concuerdan con Shue en que siempre los derechos positivos imponen tanto deberes positivos como negativos, véase: FABRE, Cécile, Social Rights under the Constitution. Government and the Decent Life (Oxford, Clarendon Press, 2000).

${ }^{19}$ Es evidente que los gastos en seguridad de algunos países hoy -entre los que hay que incluir los costes de defensa interna como externa- son muy superiores a las inversiones en educación o salud.

${ }^{20}$ JACOBS, Lesley, Rights and Deprivation (Oxford, Clarendon Press, 1993), pp. 3-4. 
Alexy considera que el argumento principal a favor de los derechos fundamentales sociales es, al igual que en el caso de los derechos negativos, el argumento de la libertad. "La libertad jurídica para hacer u omitir algo sin la libertad fáctica (real), es decir, sin la posibilidad fáctica de elegir entre lo permitido, carece de todo valor. De esto se trata cuando Lorenz von Stein dice "la libertad es sólo real cuando se poseen las condiciones de la misma, los bienes materiales y espirituales en tanto presupuestos de la autodeterminación" o cuando el Tribunal Constitucional Federal (alemán) expresa "el derecho de libertad no tendría valor alguno sin los presupuestos fácticos para poder hacer uso de él" ${ }^{21}$. Basta, entonces, suponer una división de tareas entre los derechos fundamentales y el proceso político, según el cual a los primeros les corresponde preocuparse por la libertad jurídica y al segundo, por la libertad fáctica ${ }^{22}$.

Shue mantiene, a su vez, que un derecho moral provee de una base racional para la demanda justificada de goce real de ese derecho que, además, debe ser socialmente garantizado ${ }^{23}$. Entiende que ciertos derechos humanos son básicos en el sentido de que su satisfacción es necesaria, como requisito, para la satisfacción de todos los demás derechos. Según este criterio, el autor reconoce tres categorías de derechos básicos: el derecho a la seguridad; el derecho a la subsistencia; y el derecho a gozar de ciertas libertades como las libertades de participación política. Los derechos de subsistencia serían derechos básicos en la misma medida y en base a los mismos argumentos que usualmente se utilizan para defender como derechos básicos los de libertad y seguridad ${ }^{24}$. Así, como se trata de los mismos argumentos morales para el reconocimiento de los derechos económicos y sociales, podemos preguntarnos si la demanda que ellos nos hacen va tan sólo dirigida a los

${ }^{21}$ Alexy, R., cit. (n. 3), p. 487.

${ }^{22}$ ¿Por qué no es suficiente la libertad jurídica? La importancia de la libertad fáctica para las personas se puede presentar con tres ejemplos. "Para el individuo tiene importancia existencial el no tener que vivir bajo el nivel de una existencia mínima, el no estar condenado a un permanente no hacer nada y el no quedar excluido de la vida cultural de la época. Para quien se encuentra en tales situaciones deficitarias, por cierto los derechos fundamentales no carecen totalmente de valor. Justamente el menesteroso puede valorar, por ejemplo, especialmente aquellos derechos fundamentales que lo protegen, por ejemplo, del trabajo forzado y que le brindan la posibilidad de mejorar su situación a través del proceso político. Sin embargo, no hay duda de que para él tiene más importancia la superación de su situación deficitaria que las libertades jurídicas que, debido a su situación deficitaria, no le sirven para nada y que, por tanto, se convierten en "fórmulas vacías": ALEXY, cit. (n. 3), p. 488.

${ }^{23}$ Shue, H., cit. (n. 18), pp. 13-18.

${ }^{24}$ Dentro de su derecho a la subsistencia incluye el derecho a un cuidado sanitario preventivo mínimo, SHUE, H., cit. (n. 18), pp. 8-9. 
órganos del Estado o si, en cambio, se trata de una demanda que es extensible a los particulares, lo que nos adentra en la discusión relativa a cuáles son los límites de nuestra obligación respecto de terceros.

\section{MÁS ALLÁ DE LA CARIDAD ¿¿DEBERES POSITIVOS GENERALES?}

¿Podríamos afirmar que nuestras obligaciones para con los demás están asociadas a nuestra capacidad para evitar que algo malo ocurra sin que por ello sacrifiquemos nada de "importancia moral comparable"? Una tesis como esta, que se nos aparece como razonable e incluso incontrovertible es, nos recuerda Peter Singer, realmente engañosa pues si se la tuviera como guía para la acción, incluso en su versión matizada, "nuestras vidas, nuestra sociedad y nuestro mundo se modificarían de manera fundamental"25. En su famoso artículo Famine, Affluence and Morality, donde este autor denunció la crisis humanitaria que a mediados de los ' 90 hacía que en el este de Bengala miles de personas murieran por falta de comida, techo y asistencia médica, sostenía que "El sufrimiento y la muerte que allí se están produciendo no son inevitables (...) Ni los individuos ni los gobiernos pueden apelar al desconocimiento de lo que allí pasa” ¿Cuáles son las implicancias morales de una situación como esta para los individuos particularmente considerados? Singer arguye que la manera en que reaccionan quienes están en una posición económica privilegiada frente a escenarios como el bengalí no se puede justificar; "con seguridad, la forma en que nos aproximamos a las cuestiones morales en su conjunto -nuestro esquema conceptual moral- necesita ser alterado, y con él el modo de vida que ha llegado a ser dado por sentado en nuestra sociedad"26. Y es que, como revisaré a continuación, la tesis de Singer pretende demostrar que nuestras categorías morales tradicionales están distorsionadas y que la distinción secular entre deber y caridad no puede trazarse. Nuestra obligación de

${ }^{25}$ SINGER, Peter, Hambre, Riqueza y moralidad. Una vida ética. Escritos (Madrid, Taurus, 2002), p. 137.

${ }^{26}$ Ibíd., pp. 135-136. Como es sabido Peter Singer, al ser utilitarista, abraza una moral de tipo consecuencialista, lo que significa que a la hora de hacer juicios morales lo que sería finalmente portador u objeto de valor no son las acciones sino "un cierto estado de cosas". A diferencia de las teorías deontológicas que sostienen que las acciones pueden ser, en sí mismas y con independencia de su resultado, buena o mala (mentir es "malo"), las tesis consecuencialistas, como la utilitarista, se preguntan "a qué estado de cosas conducirá mi acción” pues los actos, considerados en abstracto, no son intrínsecamente valiosos. Las éticas consecuencialistas, entonces, califican una acción como buena o mala de conformidad con los resultados negativos o positivos que se sigan de ella. Véase: Singer, P., Ética práctica (2a edición, Cambridge, University Press, 1995). 
“evitar el sufrimiento" más allá de nuestro círculo cercano se relaciona con los denominados “deberes positivos generales” que Garzón Valdés define como aquellos cuyo contenido es una acción de asistencia al prójimo que requiere un sacrificio trivial y cuya existencia no depende de la identidad del obligado ni de la del (o de los) destinatario (s), ni tampoco es resultado de algún tipo de relación contractual previa ${ }^{27}$.

Se ha sostenido que la estructura básica de la moral individual está caracterizada por la división de los actos humanos en indiferentes, supermeritorios y obligatorios ${ }^{28}$, de modo que uno de los problemas de los deberes positivos generales, como los ha definido Garzón Valdés, es que no darían cabida a los límites morales que clásicamente la cultura occidental ha estimado importantes: los límites del heroísmo y la robustez de la "zona de indiferencia”. Fishkin considera que es bueno que la mayoría de nuestras acciones caigan dentro de la zona de indiferencia pues aunque "no podemos fundamentar este principio (...) este es el modo de vida predominante en el mundo" 29 . Por ello ha desarrollado -como objeción a la existencia de este tipo de deberes- su denominado "dilema de Fishkin" que sostiene que la reiteración de un sacrificio trivial eliminaría poco a poco la barrera del heroísmo y disminuiría consecuentemente la zona de los comportamientos indiferentes desde el punto de vista moral. Aceptar la vigencia de los deberes positivos generales significaría abandonar principios básicos de la moral y renunciar al "tipo de vida que damos por sentada" 30.

En el entender de Garzón Valdés, el dilema de Fishkin se produce porque éste, erróneamente, vincula sin más la nota de "generalidad" de una obligación con la exigencia de su cumplimiento simultáneo o reiterado sin limitación temporal. Además, porque no distinguiría lo que los economistas llaman "cambio de escala" y "cambio de intensidad" pues

${ }^{27}$ GaRZÓn Valdés, Ernesto, Los deberes positivos generales y su fundamentación. Instituciones suicidas. Estudios de Ética y Política (México, Paidós, 2000), pp. 127128.

${ }^{28}$ Para Fishkin "nuestras acciones pueden ser clasificadas en tres grandes apartados: i) la zona de exigencia moral definida por deberes y obligaciones, es correcto o moralmente valioso que nos conformemos a estas exigencias e incorrecto o moralmente condenable que dejemos de hacerlo; ii) la zona de lo supermeritorio, definida por acciones 'más allá de la llamada del deber' y otras acciones discrecionales que sería valioso para nosotros realizar pero que no sería incorrecto que dejáramos de realizar; y iii) la zona de lo indiferente definida por acciones que no caen bajo las clasificaciones prescriptivas morales de correcto o incorrecto, bueno o malo: ni es valioso que las realicemos ni condenable que dejemos de realizarlas": FISHKIN, James, Las fronteras de la obligación, en Doxa 3 (1986), pp. 73-74.

${ }^{29}$ Ibíd., p. 74

${ }^{30}$ Ibíd., pp. 76-77. 
Fishkin piensa que un sacrificio trivial reiterado siempre es su sacrificio trivial, lo que evidentemente no es así pues "toda reiteración de una acción en un lapso relativamente breve significa un aumento de la intensidad del esfuerzo requerido para realizarla, por lo que el costo aumenta y los actos han dejado de ser triviales". Por ello, continúa Garzón Valdés, este dilema podría solucionarse si se aceptaran las siguientes reglas: i) Todo individuo está moralmente obligado a realizar un sacrificio trivial para evitar un daño, sin necesidad de una situación contractual previa; ii) El sacrificio trivial está temporalmente delimitado, es decir, su reiteración es exigible después de haber pasado cierto tiempo de recuperación que restituya al obligado a la situación en la que se encontraba antes del sacrificio trivial; iii) Cuando se trata de deberes positivos divisibles nadie está obligado a compensar la omisión de los demás y nadie, tampoco, está obligado si quien solicita la ayuda puede superar la situación por sí mismo; y iv) Los sacrificios triviales deben ser coordinados sobre la base de la división del trabajo y la especialización ${ }^{31}$.

Juan Carlos Bayón considera que el problema de los deberes positivos generales es que se debaten entre dos extremos, las posturas de Fishkin y Nozick ${ }^{32}$ y las ideas originales de Singer. Para evitar esto es necesario alejarse de la posición que sostiene que nuestros únicos deberes son los de abstención -pues los mismos argumentos que los fundamentan prueban, a su vez, la existencia de los deberes positivos generales- e intentar sortear la posición extrema de Singer que no se conforma con prestaciones menores a aquellas que llegan hasta el punto en el que comienza la "utilidad marginal decreciente" ${ }^{33}$. Luego ¿qué deberes positivos tenemos y cuáles son sus límites? ¿Por qué definirlos desde la noción de sacrificio trivial? El debate, subraya Bayón, parece ser dónde ha de situar una moralidad crítica

${ }^{31}$ GarZón Valdés, E., cit. (n. 27), pp. 139-141.

${ }^{32}$ Nozick plantea que, desde el punto de vista moral, sólo es posible justificar la existencia de un Estado mínimo al que le está vedado cualquier pretensión de redistribución de los recursos sociales. Véase: Nozick, Robert, Anarchy, State and Utopia (Oxford, Basic Books, 1974).

${ }^{33}$ BAYÓN, Juan Carlos, Los deberes positivos generales y la determinación de sus limites, en Doxa 3 (1986), p. 35. Si bien en un principio Singer sostenía que para evitar que algo malo ocurra -como, por ejemplo, la muerte de alguien por hambredeberíamos aportar "hasta que alcancemos el nivel de utilidad marginal", es decir, hasta el punto en que dar nos signifique colocarnos en una situación peor que la que tiene aquel a quien estamos dando, reconoció después que se debía optar por una versión más moderada que nos obliga a evitar un daño a menos que, haciéndolo, sacrifiquemos algo moralmente significativo. "Aún así, actuando bajo esta norma se necesitaría un gran cambio en nuestro modo de vida”. Véase: SINGER, P., cit. (n. 25), pp. 145-146. 
el límite entre lo obligatorio y lo supererogatorio y, en consecuencia, cuál es el nivel de sacrificio que debemos alcanzar en el cumplimiento de nuestros deberes positivos generales. Si el límite se sitúa en el sacrificio trivial, debe haber una razón para ello. Luego, lo que ocurre con los juicios basados en la idea de "trivialidad" es que mediante el empleo de una noción vaga se ha tratado de suplir la carencia de un principio moral que justifique la fijación de límites. "El altruismo mínimo basado en la idea de sacrificio trivial parece que no nos lo brinda" 34 . Por ello, lo que le parece clave en esta discusión es la idea de que el valor subyacente a la actual configuración de expectativas de servicios positivos en sociedades liberales es la autonomía personal que se define como "la capacidad de optar entre planes de vida alternativos" o, como sostiene C.S. Nino, la autonomía para desarrollar la forma de vida que cada uno elija ${ }^{35}$.

Ahora, si el objetivo de la autonomía es capaz de justificar un altruismo más que mínimo ¿cuánto debemos dar? ¿Cuáles son nuestras obligaciones para con los demás? Singer nos pide que consideremos estos hechos: según los cálculos más cautos, 400 millones de personas carecen de las calorías, proteínas, vitaminas y minerales necesarios para llevar una vida tanto física como psíquicamente sana. Millones de personas pasan hambre continuamente a la vez que sufren enfermedades carenciales e infecciosas que podrían eliminarse con una dieta equilibrada. Los niños son los más afectados pues, según los estudios, 14 millones de niños menores de cinco años mueren cada año debido a los efectos combinados de la desnutrición y las infecciones. En algunas regiones del mundo, la mitad de los niños que nacen mueren antes de cumplir cinco años. Ahora, no es la falta de alimento la única dificultad a la que se enfrentan los pobres. Robert McNamara, cuando era presidente del Banco Mundial, sugirió el término de "pobreza absoluta". La pobreza con la que estamos familiarizados es una pobreza relativa, lo que quiere decir que algunos ciudadanos son pobres, en relación con la riqueza de que disfrutan sus vecinos. Pero ¿y la pobreza que existe en Mali, Haití o Etiopía? Según McNamara "La pobreza en el nivel absoluto... es vivir en el mismo límite de la existencia. Los pobres absolutos son seres humanos con graves privaciones que luchan por sobrevivir en unas circunstancias de miseria y degradación que, desde nuestras condiciones privilegiadas, casi no podemos concebir en nuestra sofisticada imaginación". Los pobres absolutos tienen "unas condiciones de vida que se caracterizan de tal forma por una desnutrición, analfabetismo, enfermedades, entorno miserable, alta mortalidad infantil y una baja esperanza

\footnotetext{
${ }^{34}$ BAYÓN, J. C., cit. (n. 33), pp. 45-46.

${ }^{35}$ Nino, C. S., cit. (n.14), p. 208.
} 
de vida, que se encuentran por debajo de cualquier definición razonable de decencia humana"36.

Peter Unger analiza cómo llevar a la práctica nuestros deberes positivos generales y nos entrega algunas estimaciones posibles para ayudar en la tarea de disminuir la pobreza mundial. Si se suma, sostiene, el coste de recolectar dinero, los costos administrativos y los costos de entregar la ayuda donde más se necesita "con 200 dólares en donaciones podríamos ayudar a transformar a un niño enfermo de 2 años en un niño sano de 6 , permitiéndole vivir decentemente los años más peligrosos de la niñez" ${ }^{37}$. En la misma línea, Singer se pregunta si es el nivel aceptado de forma convencional -es decir, dar unas pocas monedas cuando se nos aborda en la calle para una colecta- suficiente o es evidentemente demasiado bajo ¿qué nivel deberíamos defender? "Cualquier cifra que demos será arbitraria, pero se podría dar un porcentaje redondo de los ingresos de uno, digamos, el 10 por ciento, que es más que una donación simbólica y no tanto como para convertimos en santos. (Esta cifra tiene la ventaja añadida de que tiene reminiscencias del antiguo diezmo que se daba tradicionalmente a las iglesias, cuyas responsabilidades incluían el cuidado de los pobres dentro de la comunidad local a la que uno pertenecía. Quizá esta idea se podría restablecer y aplicar a la comunidad mundial)"38. No se debería, claro, instituir una cifra determinada ni como mínimo ni como máximo, pero parece válido defender que los que tienen un sueldo medio o por encima de la media, a menos que tengan un número inusual de personas a su cargo u otras necesidades especiales, deberían aportar una décima parte de sus ingresos para reducir la pobreza absoluta. Bajo cualquier nivel ético razonable, esto es lo mínimo que deberíamos dar.

Bayón reconoce que su tesis es parecida a la de Singer y que quienes la refutan fundados en que "pocos estarían dispuestos a aceptarla" se les puede responder que "de esa crítica lo mínimo que se puede decir es que carece de la más elemental imparcialidad" puesto que "aparte de Singer y unos pocos santos hay bastantes millones de personas, sin duda morales, decentes y autointeresadas, a las que sería facilísimo "vender" la adopción de una máxima semejante: todos los que están en peligro de muerte por inanición" 39 . Cualquier egoísta racional que se encontrara en una posición de imparcialidad como la posición original de Rawls, aceptará reemplazar las actuales reglas sobre la "estructura básica de la moral individual" por un

\footnotetext{
${ }^{36} \mathrm{McNamara}$, citado por SiNGER, Ética práctica, cit. (n. 26), pp. 218 ss.

${ }^{37}$ Unger, Peter, Living High and Letting Die. Our Illusion of Innocence (Oxford, University Press, (1996), p. 148.

${ }^{38}$ Singer, P., cit. (n. 25), pp. 218 ss.

${ }^{39}$ BAYÓN, J. C., cit. (n. 33), p. 54.
} 
principio de "altruismo más que mínimo". Por ello, concluye, "si estamos hablando de moralidad y no de sondeos de opinión, lo que resulta relevante es si un determinado principio sería aceptable para un sujeto hipotético que hace suyo el punto de vista moral (llámese "espectador imparcial", "preferidor racional" o de cualquier otra manera). Otra cosa es que la mayor parte de nosotros, en los países desarrollados, estemos interesados no sólo en evitarnos los sacrificios que habríamos de soportar, sino que también en preservar nuestra buena conciencia negándonos a aceptar su exigibilidad" 40 . En fin "una cosa es la incapacidad de nuestro razonamiento práctico para alumbrar una posición moral coherente y otra muy distinta nuestra escasa disposición a aceptar un principio moral que quiebre nuestra buena conciencia y exige un sacrificio de nuestros intereses" ${ }^{41}$

La ética de mínimos en la que vivimos no lograría, entonces, suplir la carencia de un principio moral que justifique la actual fijación de límites entre lo "debido" y lo "no debido". No parece suficiente que las personas con ingresos medios o altos cumplan con su deber ético para con los demás sólo pagando impuestos, incluso aunque ellos sean altos. Los límites que este altruismo mínimo establece, y que parecemos aceptar tan cómodamente, permiten que, sin sustento moral alguno, muchos sostengan: Sé que, de acuerdo con la FAO, cerca de 25 mil personas mueren de hambre cada día pero, como yo pago mis impuestos, no tengo ningún deber respecto de ellos. Este tipo de razonamiento resulta, según se ha argumentado, suficientemente débil como para exigirnos volver a reflexionar sobre qué es lo que realmente podemos defender, aun cuando ello nos lleve hasta el punto de hacernos dudar si estamos dispuestos a tomar en serio sus resultados y a actuar en consecuencia. El nivel mínimo de cooperación social que defiende nuestra actual ética de mínimos es el que sustenta hoy desigualdades indignantes tanto dentro como fuera de las fronteras de los Estados, y ese estado de cosas no puede ser moralmente correcto.

\section{CONCLUSIÓN}

Al principio de este artículo me propuse reflexionar sobre la naturaleza de los derechos sociales y sobre si ellos y los derechos civiles y políticos son derechos que, como defiende Ruiz Miguel, conforman una categoría unitaria en lo importante: en su carácter básico asociado a la dignidad y autonomía moral humana. Por ello, inicié el análisis rechazando las posturas que sostienen la clasificación estricta de los derechos en positivos

\footnotetext{
${ }^{40}$ Ibíd., p. 53.

${ }^{41}$ Ibíd., p. 54.
} 
y negativos para negar la existencia de los segundos como "verdaderos derechos". No parece justificado sostener, de la mano de Hierro, que tener "un derecho es tener una necesidad cuya satisfacción hay razones suficientes para exigir en todo caso" lo que no ocurriría en el caso de "la escasez" de modo que no habría motivos para sostener la existencia de ciertos derecho ${ }^{42}$ ¿Significa esto que, en países relativamente pobres, las personas simplemente no tendrían derechos de tipo económico o social -como el derecho a un mínimo sanitario decente o a una vivienda básica? Si decimos que los derechos básicos son facultades o títulos que las personas poseen por el solo hecho de ser tales y que son, además, prerrequisitos para el ejercicio de la autonomía, debiéramos acordar que la escasez no puede ser un argumento definitivo para desconocer su existencia, aunque sí pueda ser una razón para definir su contenido, por sobre el mínimo, conforme a una cierta realidad político-social.

En esta línea, concuerdo con Ruiz Miguel en la necesidad de distinguir entre el reconocimiento de un derecho, es decir, su carácter universal, y los problemas asociados a su realización efectivamente universal, esto es, la diferencia entre el derecho propiamente dicho -que no deja de ser un derecho universal-y su incumplimiento en la práctica "que no sólo no impugna aquella universalidad sino que denuncia su ausencia" ${ }^{43}$. No debemos olvidar que no sólo por razones económicas es posible el desconocimiento de los derechos. Durante las dictaduras políticas o religiosas también se produce el incumplimiento "en la práctica" de derechos de todo tipo, tanto positivos como negativos. ¿Debemos concluir que, entonces, las mujeres simplemente no tienen el derecho humano a la libre expresión, asociación, reunión, propiedad, debido proceso, participación política, integridad física etc. sólo porque viven en Arabia Saudita , Afganistán o Irán?

En fin, defender el carácter universal de los derechos humanos significa argumentar que, al menos ciertos derechos sociales -como el derecho a un mínimo sanitario-, son derechos que debemos poder justificar más allá de su concreción legal y de la situación económica de un Estado en particular. "No hablamos de unos derechos que unos tienen y otros no en función del sistema jurídico en que vivan. Hay una imposibilidad conceptual de afirmar simultáneamente que los derechos humanos son universales y que son producto del orden jurídico positivo, porque la condición de sujeto de un sistema jurídico excluye la noción de universalidad de que estamos hablando" ${ }^{44}$. De este modo, cuando afirmamos que los derechos sociales

\footnotetext{
${ }^{42}$ Hierro, L., cit. (n. 1), p. 57.

${ }^{43}$ Ruiz Miguel, A., cit. (n. 7), p. 662.

${ }^{44}$ LaPORTA, Francisco, Algunos problemas de los deberes positivos generales. Observaciones a un artículo de Ernesto Garzón Valdés, en Doxa 3 (1986), pp. 32-33.
} 
son derechos humanos universales somos testigos del paso de la solidaridad basada en pautas de "caridad" a la solidaridad fundada en pautas de exigencia ética fuerte o de "justicia”" 5 .

La consideración de los derechos sociales como derechos humanos positivos y exigibles se deduce después de demostrar el carácter artificial de la división entre derechos positivos y negativos -especialmente en base al carácter prestacional que, supuestamente, sólo tendrían unos y no otros- y de abogar a favor de su clasificación como derechos humanos "universales" conforme al argumento de la libertad real y de la autonomía. Quienes cuestionan la universalidad de los derechos sociales y económicos lo hacen, como vimos, en base al argumento de que los sujetos obligados a proporcionar los bienes y servicios que son objeto de esos derechos muchas veces -como ocurre con los países pobres- carecen de los recursos necesarios de modo que, como nadie está obligado a lo imposible, no se estaría violando ningún derecho. El problema de esta argumentación es que omite, sin más, la posibilidad de considerar que la universalidad de los derechos humanos significa, también, la universalidad de los "deberes" a ellos asociados, lo que permite cuestionar la importancia moral que se da a las fronteras nacionales para efecto de reconocer o desconocer derechos fundamentales. Y es que existen en la actualidad variados organismos internacionales de ayuda a los países pobres (como, por ejemplo, las Naciones Unidas o el Banco Mundial) que parecen reconocer la obligación moral de "todas" las naciones del mundo de aunar esfuerzos para acabar con los grandes problemas asociados a la pobreza endémica en ciertas regiones del planeta. Estos organismos internacionales trabajan basados en el principio de universalidad de los derechos humanos y fundados en una interpretación extensiva de los deberes asociados a esos derechos. Es decir, podemos afirmar que todas las personas tienen los mismos derechos básicos, no sólo en base a los fundamentos morales recién expuestos sino que, también, de la mano de una identificación amplia de los sujetos obligados a garantizar los derechos humanos de las personas y una concepción nueva sobre la relevancia moral de las fronteras nacionales.

En esta misma línea, la extensión de las obligaciones asociadas al cumplimiento de los derechos sociales no se debe limitar a los Estados desarrollados, sino que también a los individuos económicamente favorecidos que, reconociendo la obligatoriedad de sus deberes positivos generales, extiendan sus obligaciones más allá de lo que les exigiría una ética de mínimos. Aun cuando sea difícil imponer la ética de máximos que alguna vez planteó Singer, sí podemos avanzar a un "altruismo más que

${ }^{45}$ Ibíd. 
mínimo" que considere moral y jurídicamente erróneo el "estilo de vida" que los privilegiados del mundo llevamos hoy adelante sin remordimientos ¿Cómo será esa ética futura, qué límites tendrá y cómo transformará el mundo? Es difícil saberlo, pero sí es posible que, con el tiempo, termine imponiéndose la idea de que dar dinero para que las personas pobres vivan dignamente no es una buena "obra de caridad" que se nos debe agradecer, sino que es nuestro deber. No desaparecerá, entonces, la distinción entre acto supererogatorio y deber positivo general, sino que tendremos que volver a definirla de un modo más adecuado a lo que nos indique nuestro razonamiento sobre ética práctica.

[Recibido el 25 de mayo y aceptado el 21 de septiembre de 2009].

\section{BIBLIOGRAFÍA}

Abramovich, Víctor - Courtis, Christian, Los derechos sociales como derechos exigibles (Madrid, Trotta, 2002).

AlEXY, Robert, Teoría de los derechos fundamentales (Centro de Estudios Políticos y Constitucionales. Madrid, 2002).

BAYÓN, Juan Carlos, Los deberes positivos generales y la determinación de sus límites, en Doxa 3 (1986).

Fabre, Cécile, Social Rights under the Constitution. Government and the Decent Life (Oxford, Clarendon Press, 2000).

FishKIN, J. S., Las fronteras de la obligación, en Doxa 3 (1986).

GARZÓN VALDÉs, Ernesto, Los deberes positivos generales y su fundamentación. Instituciones suicidas. Estudios de Ética y Política (México, Paidós, 2000).

Gewirth, Alan, ¿Are All Rights Positive? En Philosophy \& Public Affairs 30 (2002) 3.

Hierro, Liborio, ¿Derechos humanos o necesidades humanas? Problemas de un concepto, sistema (Madrid, 1982).

Hohfeld, W. N., Some Fundamental Legal Conceptions as Applied to Judicial Reasoning, en Yale Law Journal 23 (1913).

Holmes, S. - Sunstein, C. R., The Cost of Rights: Why Liberty Depends on Taxes (Nueva York, W.W. Norton \& CO., 1999).

JaCoBs, Lesley A., Rights and Deprivation (Oxford, Clarendon Press, 1993).

LAPORTA, Francisco, Algunos problemas de los deberes positivos Generales. Observaciones a un artículo de Ernesto Garzón Valdés. Doxa 3 (1986).

Nino, Carlos Santiago, Sobre los derechos sociales. Derechos sociales y derechos de las minorías, en Carbonell, M. - J. A. Cruz Parcero - R. VÁzQuez (compiladores) (México, Universidad Nacional Autónoma de México, 2000).

Nozick, Robert, Anarchy, State and Utopia (Oxford, Basic Books, 1974).

Pérez Luño, A. E., Derechos humanos, Estado de derechos y Constitución (Madrid, Tecnos, 2004).

Prieto SAnChís, Luis, Los derechos sociales y el principio de igualdad sustancial. Derechos sociales y derechos de las minorías, en Carbonell, M. - Cruz ParCero, J. A. - VÁzQuez, R. (compiladores) (México, Universidad Nacional Autónoma de México, 2000). 
Ruiz Miguel, Alfonso, Derechos liberales y derechos sociales, en Doxa 15-16 (1994). Shue, Henry, Basic Rights (2a edición, Princeton University Press, 1996).

Singer, Ética práctica (2a edición, Cambridge, University Press, 1995).

Singer, Peter, Hambre, riqueza y moralidad. Una vida ética. Escritos (Madrid, Taurus, 2002),

Unger, Peter, Living High and Letting Die. Our Illusion of Innocence (Oxford, University Press, (1996). 